Check for updates

Cite this: Mater. Chem. Front., 2020, 4, 507

Received 19th September 2019, Accepted 28th November 2019

DOI: $10.1039 / c 9 q m 00587 k$

rsc.li/frontiers-materials

\title{
The synthesis of nitrogen and sulfur co-doped graphene quantum dots for fluorescence detection of cobalt(II) ions in water +
}

\author{
Wissuta Boonta, (D) ${ }^{a}$ Chanon Talodthaisong, ${ }^{a}$ Suchinda Sattayaporn, ${ }^{b}$ \\ Chiraporn Chaicham, ${ }^{c}$ Anusak Chaicham, ${ }^{d}$ Somboon Sahasithiwat, ${ }^{e}$ \\ Laongdao Kangkaew ${ }^{e}$ and Sirinan Kulchat (D) *a
}

\begin{abstract}
A fluorescent sensor based on nitrogen and sulfur co-doped graphene quantum dots (N,S-GQDs) has been developed for the convenient, sensitive, and selective detection of cobalt(II) ions $\left(\mathrm{Co}^{2+}\right)$. $\mathrm{Co}^{2+} \mathrm{can}$ quench the fluorescence intensity of N,S-GQDs through metal-ligand interaction between the metal ions and the surface functional groups of the fluorescent probe. Furthermore, the addition of $\mathrm{Co}^{2+}$ induces the aggregation of N,S-GQDs, resulting in an enhancement of UV-Visible absorption at $430 \mathrm{~nm}$ and color change from colorless to yellow-brown within 3 minutes. The fluorescence intensity of N,S-GQDs can be used to sense $\mathrm{Co}^{2+}$ under the optimal circumstances with a detection limit of $1.25 \mu \mathrm{M}$ and a working linear range of $0-40 \mu \mathrm{M}$. In addition, the sensor probe was applied successfully to the determination of $\mathrm{CO}^{2+}$ in real water samples. Due to its low cytotoxicity, the proposed sensor may potentially be applied in environmental and biological fields.
\end{abstract}

\section{Introduction}

Graphene quantum dots (GQDs) are $\mathrm{sp}^{2}$ hybridized carbonbased fluorescent materials ${ }^{1}$ with low dimensionality (0D), and a size range between 1-10 $\mathrm{nm} \cdot{ }^{2-6}$ GQDs were first synthesized by Pan et al. in 2010 using a simple hydrothermal method to cut down graphene sheets (GSs). As such GQDs have a similar crystalline structure to single or few layer GSs but with an average diameter of $9.6 \mathrm{~nm} .^{7}$ GQDs exhibit many favourable material properties, including excellent dispersivity in water and high photostability, and are sources of cheap raw materials that are easily scalable. ${ }^{2,4,8-10}$ Moreover, GQDs also have the advantages of high biocompatibility and nontoxicity. ${ }^{11,12}$ Thus, they can be

\footnotetext{
${ }^{a}$ Materials Chemistry Research Center, Department of Chemistry and Center of Excellence for Innovation in Chemistry, Faculty of Science, Khon Kaen University, Khon Kaen, 40002, Thailand. E-mail: sirikul@kku.ac.th; Fax:+66-432-02373; Tel: $+66-430-09700$

${ }^{b}$ Synchrotron Light Research Institute (Public Organization), 111 University Avenue, Muang District, Nakorn Ratchasima, 30000, Thailand

${ }^{c}$ Supramolecular Chemistry Research Unit, Department of Chemistry, Faculty of Science, Chulalongkorn University, Phayathai Road, Patumwan, Bangkok, 10330, Thailand

${ }^{d}$ Faculty of Science, Department of Chemistry, Chandrakasem Rajabhat University, Bangkok, 10900, Thailand

${ }^{e}$ National Metal and Materials Technology Center, National Science and Technology Development Agency, Pathumthani, 12120, Thailand

$\dagger$ Dedicated to Prof. Jean-Marie Lehn on the occasion of his 80th birthday

\# Electronic supplementary information (ESI) available. See DOI: 10.1039/c9qm00587k
}

applied for various applications, for instance, (bio)chemical sensing, ${ }^{10,13-15}$ catalysis, ${ }^{16,17}$ drug delivery, ${ }^{18,19}$ and bioimaging. ${ }^{9,20}$ Band-gap energy tuning by doping atomic impurities into GQDs, such as boron, nitrogen, phosphorus, and sulfur including co-doped atoms, is an effective method to control the optical properties of GQDs. Most importantly for this work however, quantum confinement effects in GQDs make their photoluminescence (PL) properties highly sensitive to size, layer, shape and edge configuration, and thus potentially excellent environmental sensors. ${ }^{821-23}$

One pressing environmental sensing challenge is water, soil, and food resource contamination by toxic heavy metals, which causes critical problems for both eco-systems and human health. ${ }^{24}$ Contamination of soil and water with heavy metals such as lead $(\mathrm{Pb})$, chromium $(\mathrm{Cr})$, manganese $(\mathrm{Mn})$, iron $(\mathrm{Fe})$, cobalt $(\mathrm{Co})$, nickel $(\mathrm{Ni})$, copper $(\mathrm{Cu})$, zinc $(\mathrm{Zn})$, and mercury $(\mathrm{Hg})$ is an environment issue on a global scale and becoming increasingly significant as a result of the increase of heavy industries..$^{25,26}$

Cobalt ions $\left(\mathrm{Co}^{2+}\right)$ are a significant, water soluble heavy metal contaminant. In trace amounts they are an essential element in human biology with roles including as a component of cyanocobalamin (vitamin $\mathrm{B}_{12}$ ) and cobalt-containing co-enzymes. ${ }^{27}$ They also catalyze some reactions such as methionine synthesis, metabolism of purines and folates, treatment of high cholesterol, and red blood cell production. ${ }^{27-31}$ However, exposure to excessive levels of cobalt ions and cobalt compounds in daily life through breathing air, soil, water, and diet causes many deleterious side 
effects to human health including cardiotoxicity and low cardiac output. $^{27,32}$ Moreover, cobalt oxides may affect the heart and lungs and are possibly carcinogenic, causing several diseases, for example, asthma, thyroid damage, and memory impairment. ${ }^{27,33-35}$ Therefore, the determination of cobalt ions in the environment, especially in drinking water and natural waters at concentration ranges hazardous to human health, is of crucial concern.

Up to the present time, many analysis methods have been developed to detect cobalt ions, for example, electrochemical methods, ${ }^{36,37}$ inductively coupled plasma optical emission spectrometry (ICP-OES), ${ }^{38}$ and colorimetric methods. ${ }^{32,39-41}$ Among these techniques, fluorometry has attracted much interest for metal sensing owing to its simplicity, high sensitivity, rapid response, low-cost detection, and convenience. Over the last few years, several kinds of fluorescent probes such as carbon dots, ${ }^{42}$ nitrogen-doped carbon dots, ${ }^{43}$ phosphorus and nitrogen co-doped carbon quantum dots, ${ }^{44}$ nitrogen and sulfur co-doped carbon-based dots, ${ }^{45}$ and thioglycolic acid-capped $\mathrm{CuInS}_{2} / \mathrm{ZnS}$ quantum dots ${ }^{46}$ have been reported for the efficient detection of $\mathrm{Co}^{2+}$.

Herein, we develop a fluorescent sensor system for cobalt ions in real water samples utilizing nitrogen and sulfur co-doped graphene quantum dots (N,S-GQDs). The N,S-GQDs are prepared from low-cost raw materials using a simple hydrothermal method. We used citric acid as a carbon source, and cysteamine hydrochloride for the nitrogen and sulfur sources. We show that the proposed sensor system can be applied to detect $\mathrm{Co}^{2+}$ sensitively and selectively in real samples. Furthermore, the sensor can be fabricated on paper strips for visual screening with potential for further development of simple analytical devices.

\section{Experimental section}

\subsection{Materials}

Citric acid $\left(\mathrm{C}_{6} \mathrm{H}_{8} \mathrm{O}_{7}, 99.5 \%\right)$, sodium hydroxide anhydrous ( $\mathrm{NaOH}, 99 \%)$, lead(II) nitrate $\left(\mathrm{Pb}\left(\mathrm{NO}_{3}\right)_{2}, 99 \%\right)$, nickel(II) nitrate hexahydrate $\left(\mathrm{Ni}\left(\mathrm{NO}_{3}\right)_{2} \cdot 6 \mathrm{H}_{2} \mathrm{O}, 99 \%\right)$, cadmium nitrate tetrahydrate $\left(\mathrm{Cd}\left(\mathrm{NO}_{3}\right)_{2} \cdot 4 \mathrm{H}_{2} \mathrm{O}, 99 \%\right)$, and mercury(II) chloride $\left(\mathrm{HgCl}_{2}, \geq 99.5 \%\right)$ were purchased from Carlo Erba. Cysteamine hydrochloride $\left(\mathrm{C}_{2} \mathrm{H}_{7} \mathrm{NS} \cdot \mathrm{HCl}, \quad \geq 98 \%\right)$, manganese(II) nitrate tetrahydrate $\left(\mathrm{Mn}\left(\mathrm{NO}_{3}\right)_{2} \cdot 4 \mathrm{H}_{2} \mathrm{O}, \geq 97 \%\right)$, dimethyl sulfoxide (DMSO, $\geq 99.5 \%$ ), fetal bovine serum (FBS), and LUDOX ${ }^{\circledR}$ AS-40 colloidal silica, $40 \mathrm{wt} \%$ suspension in water were purchased from Sigma Aldrich. Tris(hydroxymethyl)methylamine $\left(\mathrm{C}_{4} \mathrm{H}_{11} \mathrm{NO}_{3}, 99.8 \%\right)$, sodium nitrate $\left(\mathrm{NaNO}_{3}, \geq 99 \%\right)$, magnesium nitrate $\left(\mathrm{Mg}\left(\mathrm{NO}_{3}\right)_{2}, 99.4 \%\right)$, barium nitrate $\left(\mathrm{Ba}\left(\mathrm{NO}_{3}\right)_{2}, \geq 99 \%\right)$, aluminium nitrate $\left(\mathrm{Al}\left(\mathrm{NO}_{3}\right)_{3}\right.$, $98 \%)$, and cobalt(II) nitrate hexahydrate $\left(\mathrm{Co}\left(\mathrm{NO}_{3}\right)_{2} \cdot 6 \mathrm{H}_{2} \mathrm{O}, \geq 98 \%\right)$ were purchased from Univar. Hydrochloric acid (37\%) was purchased from RCI Labscan. Potassium nitrate $\left(\mathrm{KNO}_{3}, \geq 99 \%\right)$ was purchased from $\mathrm{BDH}$. Calcium chloride $\left(\mathrm{CaCl}_{2}, 95 \%\right)$ was purchased from Scharlau. Iron(III) nitrate $\left(\mathrm{Fe}\left(\mathrm{NO}_{3}\right)_{3}, 98.5 \%\right)$ was purchased from QRëC. Copper(II) nitrate trihydrate $\left(\mathrm{Cu}\left(\mathrm{NO}_{3}\right)_{2} \cdot 3 \mathrm{H}_{2} \mathrm{O}\right.$, $\geq 99 \%)$ and zinc nitrate hexahydrate $\left(\mathrm{Zn}\left(\mathrm{NO}_{3}\right)_{2} \cdot 6 \mathrm{H}_{2} \mathrm{O}, \geq 99 \%\right)$ were purchased from Fluka. Penicillin, streptomycin, and RPMI 1640 medium were obtained from Gibco $^{\mathrm{TM}}$. 3-(4,5-Dimethylthiazol-2-yl)2,5-diphenyltetrazolium bromide (MTT reagent) was obtained from Invitrogen ${ }^{\mathrm{TM}}$. Ultrapure water with specific resistivity of 18.2 $\mathrm{M} \Omega \mathrm{cm}$ and conductivity of $0.055 \mu \mathrm{S} \mathrm{cm}^{-1}$ (Millipore water purification system) from ELGA- Ultra GE MK2 was used to prepare all aqueous solutions.

\subsection{Synthesis of N,S-GQDS}

Hydrothermal procedures were applied to synthesize N,S-GQDs by modifying a previous report. ${ }^{16}$ Briefly, citric acid $(0.21 \mathrm{~g}$, $1 \mathrm{mmol})$ and cysteamine. $\mathrm{HCl}(0.2314 \mathrm{~g}, 3 \mathrm{mmol})$ were dissolved in $5 \mathrm{~mL}$ of water, followed by stirring until a clear solution was observed. After that, the clear solution was sealed in a $20 \mathrm{~mL}$ Teflon-lined autoclave and heated hydrothermally at $160{ }^{\circ} \mathrm{C}$ for 4 hours. Then, the autoclave was taken out and cooled to RT. The thus obtained yellow solution of N,S-GQDs was purified by centrifugation at $6000 \mathrm{rpm}$ for $20 \mathrm{~min}$ to remove unreacted residues and impurities. The purified solution was kept at $-20{ }^{\circ} \mathrm{C}$ before freeze-drying in order to obtain solid GQDs. Aqueous solutions of the GQDs for characterization were made up to $0.2 \mathrm{M}$ (as calculated by comparison with the original carbon source (citric acid)).

\subsection{Characterizations}

Fluorescence and absorption spectra were monitored using a RF-6000 spectrofluorometer (Shimadzu, Japan) with slit widths at $5 \mathrm{~nm} / 5 \mathrm{~nm}$ and a Cary60 Agilent Technologies spectrofluorometer, respectively, using $1.0 \mathrm{~cm}$ quartz cells. The $\mathrm{pH}$ values of the solutions were indicated using a UB-10 Ultra Basic pH meter (Denver Instrument). The micrographs of GQDs were obtained by transmission electron microscope (TEM) using a Tecnai $\mathrm{G}^{2}-20$ (FEI, Netherland) system at an acceleration voltage of $200 \mathrm{kV}$. Attenuated total reflection Fourier transform infrared (ATR-FT-IR) spectra were studied to determine the surface functional groups of the GQDs using a Bruker TENSOR 27 spectrometer by scanning from 4000 to $600 \mathrm{~cm}^{-1}$. FT-Raman spectra were measured using a PerkinElmer Spectrum GX FTIR/ FT-Raman spectrometer. The powder X-ray diffraction (XRD) pattern was performed using a PANalytical EMPYREAN X-ray diffractometer with $\mathrm{Cu} \mathrm{K} \alpha$ radiation $(\lambda=1.5406 \AA)$ in the $2 \theta$ range of $5-50^{\circ}$. The zeta potential of GQDs in aqueous suspension was monitored using a Zetasizer Nano ZS (Malvern Instrument, UK). Furthermore, X-ray photoelectron spectroscopy (XPS) was performed using a PHI5000 Versa Probe II (ULVAC-PHI, Japan) at the SUT-NANOTEC-SLRI joint research facility, BL 5.3, Synchrotron Light Research Institute (SLRI), Thailand. Monochromatic Al K $\alpha$ X-rays $(1486.6 \mathrm{eV})$ were used as an excitation source. The fluorescence lifetimes were measured using a FluoroMax-4 spectrofluorometer equipped with a timecorrelated single photon counting unit (TCSPC). Scattered excitation light from $0.01 \%$ LUDOX AS-40 aqueous solution was used for determining the instrument response function (IRF). The NMR spectra were recorded using a Bruker Avance $400 \mathrm{MHz}$ spectrometer (Bruker, Germany) using $\mathrm{D}_{2} \mathrm{O}$ as a solvent. The high-resolution transmission electron microscopy (HRTEM) was studied using a Thermo Scientific TALOS F200X system. 


\subsection{Fluorescent sensing of $\mathrm{Co}^{2+}$ ions}

Experiments for the determination of $\mathrm{Co}^{2+}$ ions were undertaken at RT. Firstly, $\mathrm{Co}\left(\mathrm{NO}_{3}\right)_{2} \cdot 6 \mathrm{H}_{2} \mathrm{O}$ was dissolved in water for preparing a stock solution of $10 \mathrm{mM} \mathrm{Co}^{2+}$ ions. Stock solutions of other metal ions were prepared by the same procedure using their respective salts. For a typical process, to a $10 \mathrm{~mL}$ volumetric flask were added in order: $10 \mu \mathrm{L}$ of $0.2 \mathrm{M}$ of N,S-GQDs solution, $500 \mu \mathrm{L}$ of 1.0 M Tris-HCl buffer ( $\mathrm{pH} 9.0$ ), and a known volume of a standard metal ion solution (depending on the experiment). Next, the mixture was adjusted to $10.00 \mathrm{~mL}$ with ultrapure water. Finally, the fluorescence intensity of the solution was monitored at $\lambda_{\mathrm{em}} / \lambda_{\mathrm{ex}}=425 / 345 \mathrm{~nm}$. The selectivity for $\mathrm{Co}^{2+}$ was confirmed by comparison with other metal ions under the same circumstances. All determinations were repeated at least three times.

\subsection{Determination of $\mathrm{Co}^{2+}$ ions in real samples}

Real water samples were obtained from the second floor of the Department of Chemistry, Faculty of Science, Khon Kaen University. Samples included commercial drinking water, drinking water from a water dispenser and tap water (from an inorganic laboratory). The spiked samples were made up by adding controlled concentrations of $\mathrm{Co}^{2+}$ into each real water sample.

\subsection{Preparation of paper strips for $\mathrm{Co}^{2+}$ ion detection}

First of all, the filter paper (Whatman ${ }^{\mathrm{TM}}$ No. $1, \phi=110 \mathrm{~mm}$ ) was cut to dimensions of $1.5 \mathrm{~cm}(W) \times 1.5 \mathrm{~cm}(L)$. The N,S-GQDbased paper strips were produced by immersion of the filter paper into solutions of $20 \mathrm{mM} \mathrm{N}, \mathrm{S}-G Q D s$ in $0.5 \mathrm{M}$ Tris-HCl buffer $\mathrm{pH} 9.0$ for $20 \mathrm{~min}$ under sonication. The paper strips were then removed from the solution and dried for $30 \mathrm{~min}$ at RT. Then $\mathrm{Co}^{2+}$ solutions of different concentrations were dropped on the paper strips. After that, the paper strips were also dried at RT for about $30 \mathrm{~min}$. Finally, the emission of the paper strips was monitored under UV lamp irradiation with a wavelength of $365 \mathrm{~nm}$ for $\mathrm{Co}^{2+}$ detection.

\subsection{MTT assays}

The cytotoxicity of the N,S-GQDs was analyzed by MTT assay. Typically, HeLa cells ( 8000 cells $/ 100 \mu \mathrm{L}$ ) were first cultured in a 96-well plate containing RPMI-1640 medium supplemented with streptomycin $\left(10000 \mu \mathrm{g} \mathrm{mL} \mathrm{m}^{-1}\right)$, penicillin $\left(10000 \mathrm{U} \mathrm{mL}^{-1}\right)$, and $10 \%$ fetal bovine serum (FBS). Every cell was collected under a humidified atmosphere at $37{ }^{\circ} \mathrm{C}$ and $5 \% \mathrm{CO}_{2}$ to adhere cells to the surface. Then, the medium was replaced with fresh RPMI1640 supplemented with various concentrations of N,S-GQDs $(0,0.5,1.0,1.5,2.0,2.5$ and $3.0 \mathrm{mM})$, and incubated at $37{ }^{\circ} \mathrm{C}$ for 24, 48 and 72 hours. After incubation, the culture medium was removed and $10 \mu \mathrm{L}$ of $5.0 \mathrm{mg} \mathrm{mL}{ }^{-1}$ MTT reagent was added into each well. Then, the cells were incubated with MTT at $37{ }^{\circ} \mathrm{C}$ for 2.5 hours, at which time the solution was replaced by an MTT solution with $100 \mu \mathrm{L}$ of DMSO with shaking for $10 \mathrm{~min}$ at RT. Finally, the absorbance at $550 \mathrm{~nm}$ and the reference wavelength at $655 \mathrm{~nm}$ were analyzed using a microplate reader (EZ Red 2000 microplate reader). The percent cell viabilities of all the samples were calculated as shown in the equation below.

Percent of cell viability

$$
=\frac{\mathrm{Ab}_{(550-655 \mathrm{~nm})} \text { of solvent control }-\mathrm{Ab}_{(550-655 \mathrm{~nm})} \text { of sample }}{\mathrm{Ab} \mathrm{b}_{(550-655 \mathrm{~nm})} \text { of solvent control }} \times 100
$$

\section{Results and discussion}

\subsection{Characterization of N,S-GQDs}

The optical properties of the as-prepared N,S-GQDs were first characterized by absorption and fluorescence spectroscopy as shown in Fig. 1(a and b). The absorption spectrum shows a small absorption band at $240 \mathrm{~nm}$ corresponding to $\pi \rightarrow \pi^{*}$ transitions of $\mathrm{C}=\mathrm{C}$ bonds in aromatic $\mathrm{sp}^{2}$ domains of $\mathrm{N}, \mathrm{S}$ GQDs, and a clear absorption band at $349 \mathrm{~nm}$ consistent with $\mathrm{n} \rightarrow \pi^{*}$ transitions of the $\mathrm{C}=\mathrm{O}$ bond.$^{16,47}$ The emission spectra of N,S-GQDs exhibit slight excitation-dependent emission, with the emission intensity maximum at $425 \mathrm{~nm}$ and when excitation is at $345 \mathrm{~nm}$ (Fig. 1b). That the emission wavelength and intensity depend on excitation wavelength is a common phenomenon of carbon-based dots (CDs), typically reflecting both the effect of GQD size distribution and a distribution of emissive sites on each nanoparticle. ${ }^{16,21}$

The morphology of N,S-GQDs was assessed by transmission electron microscopy (TEM). The results show that the particles are homogeneously spherical shape and well dispersed without agglomeration (Fig. 1c). The average diameter of N,S-GQD nanocrystals was calculated using the Image program and they have an average size of $3.0 \pm 1.0 \mathrm{~nm}(n=79)$ with the size distribution in the range of 1.1-5.4 nm (inset of Fig. 1c). The HRTEM image of N,S-GQDs (Fig. 2d) reveals that most of the N,S-GQDs have a high degree of crystallinity with the lattice
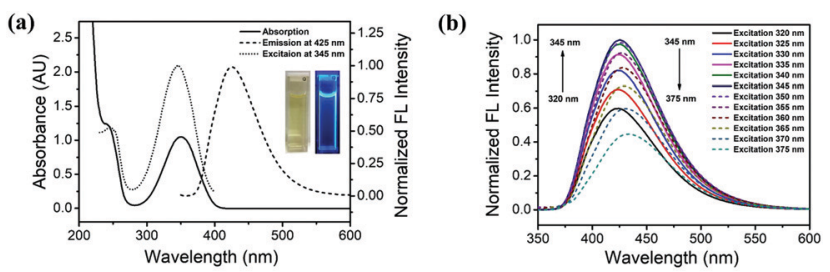

(c)

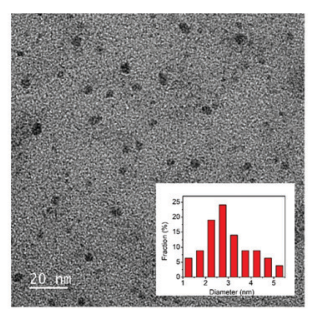

(d)

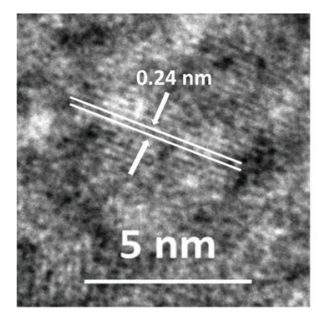

Fig. 1 (a) The absorption, fluorescence emission, and fluorescence excitation spectra of N,S-GQDs $\left(\lambda_{\mathrm{em}} / \lambda_{\mathrm{ex}}=425 / 345 \mathrm{~nm}\right)$. Insets are the corresponding photographs of N,S-GQDs taken under daylight (left) and UV-light irradiation of $365 \mathrm{~nm}$ (right). (b) Emission spectra of N,S-GQDs recorded for progressively longer excitation wavelengths in $5 \mathrm{~nm}$ increments from $320 \mathrm{~nm}$ to $375 \mathrm{~nm}$. (c) TEM image of N,S-GQDs (3.0 $\pm 1.0 ; n=79)$. Inset is the size distribution of N,S-GQDs. (d) The HRTEM image with measured lattice spacing of N,S-GQDs. 


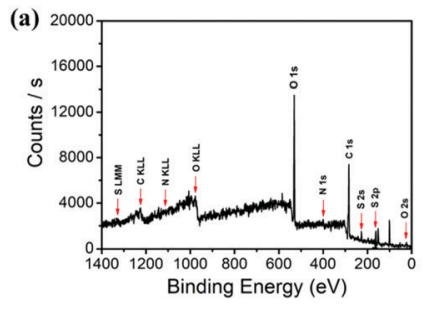

(d)

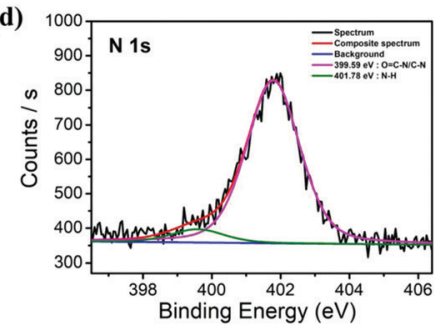

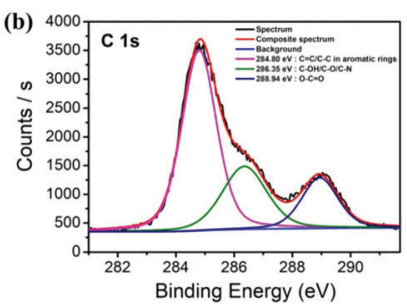
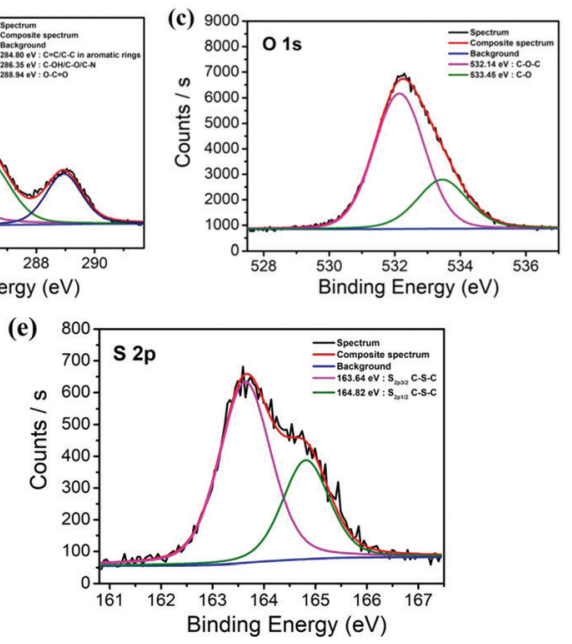

Fig. 2 (a) XPS full scan spectra of N,S-GQDs and ( $b, c$, d, and e) the XPS analysis of $C_{1 s}, O_{1 s}, N_{1 s}$, and $S_{2 p}$ of N,S-GQDs, respectively.

spacing of $0.24 \mathrm{~nm}$, indicating the (1120) lattice fringes of graphene. ${ }^{15}$ The excellent optical and morphological properties of the synthesized N,S-GQDs suggest that they can be useful for further fabrication of sensor probes to detect metal ions.

The XRD pattern of N,S-GQDs exhibits a broad diffraction peak at $23.47^{\circ}$ consistent with the (002) plane of graphite, attributed to a highly disordered graphene-like structure for the N,S-GQDs (Fig. S1A, ESI $\$$ ). ${ }^{15,48}$ In addition, Raman spectrum confirm the successful synthesis of N,S-GQDs as described in Fig. S1b (ESI $\$$ ). The disordered (D) band at $1385 \mathrm{~cm}^{-1}$ and the crystalline (G) band at $1535 \mathrm{~cm}^{-1}$ indicate the existence of $\mathrm{sp}^{3}$ defect sites and in-plane vibrations of $\mathrm{sp}^{2}$-hybridized graphitic carbon atoms on the surface of the N,S-GQDs, respectively. ${ }^{49,50}$

The chemical compositions and surface functional groups of the N,S-GQDs were studied by X-ray photoelectron spectroscopy (XPS) and attenuated total reflection Fourier transform infrared spectroscopy (ATR-FT-IR). The result as shown in Fig. 2a indicates the full range XPS spectra of the as-prepared material. It can be seen that there are four elements in the spectrum as shown in the following details: $\mathrm{C}_{1 \mathrm{~s}}(284.66 \mathrm{eV}), \mathrm{O}_{1 \mathrm{~s}}$ (530.56 eV), $\mathrm{N}_{1 \mathrm{~s}}(398.83 \mathrm{eV}), \mathrm{S}_{2 \mathrm{p}}(162.32 \mathrm{eV})$, and $\mathrm{S}_{2 \mathrm{~s}}(228.03 \mathrm{eV})$. The high resolution spectrum of $\mathrm{C}_{1 \mathrm{~s}}$ has also been deconvoluted into three single peaks at $284.80 \mathrm{eV}, 286.35 \mathrm{eV}$, and $288.94 \mathrm{eV}$ corresponding to $\mathrm{C}=\mathrm{C}$ and $\mathrm{C}-\mathrm{C}$ bonds in aromatic rings, $\mathrm{C}-\mathrm{OH} /$ $\mathrm{C}-\mathrm{O} / \mathrm{C}-\mathrm{N}$, and $\mathrm{O}-\mathrm{C}=\mathrm{O}$, respectively (Fig. $2 \mathrm{~b}$ ). ${ }^{51-53}$ The $\mathrm{O}_{1 \mathrm{~s}}$ spectrum revealed the presence of $\mathrm{C}-\mathrm{O}-\mathrm{C}$ at $532.14 \mathrm{eV}$ and $\mathrm{C}-\mathrm{O}$ at $533.45 \mathrm{eV}$ as shown in Fig. $2 \mathrm{c}^{54}$ The $\mathrm{N}_{1 \mathrm{~s}}$ spectrum could be fitted with two main peaks centered at $399.59 \mathrm{eV}$ and $401.78 \mathrm{eV}$, attributed to both $\mathrm{O}=\mathrm{C}-\mathrm{N}$ and $\mathrm{C}-\mathrm{N}$, and $\mathrm{N}-\mathrm{H}$, respectively (Fig. $2 \mathrm{~d}$ ). ${ }^{42,51}$

Moreover, the high resolution spectrum of $\mathrm{S}_{2 \mathrm{p}}$ contains two spin-orbit doublet peaks of $2 \mathrm{p}_{3 / 2}$ and $2 \mathrm{p}_{1 / 2}$ at $163.64 \mathrm{eV}$ and $164.82 \mathrm{eV}$, respectively (Fig. 2e), confirming the presence of C-S-C units. ${ }^{14,51}$ The results discussed above confirm the doping of $\mathrm{N}$ and $\mathrm{S}$ heteroatoms into the graphene network via the hydrothermal method.

Importantly, the surface of the GQDs may feature specific functional groups which can influence water solubility and
PL efficiency. The ATR-FT-IR results indicate the formation of nitrogen, oxygen, and sulfur-rich groups on the N,S-GQD surface (Fig. S1c, ESI ). The broad absorption bands at around $3000-3500 \mathrm{~cm}^{-1}$ correspond to $\mathrm{O}-\mathrm{H}$ and $\mathrm{N}-\mathrm{H}$ stretches. These results suggest that there are plenty of amino, hydroxyl, and carboxylic groups on the surface of N,S-GQDs, affording its hydrophilicity. The weak broad band at $2565 \mathrm{~cm}^{-1}$ can be assigned to $\mathrm{S}-\mathrm{H}$ stretches. The two bands at $1707 \mathrm{~cm}^{-1}$ and $1623 \mathrm{~cm}^{-1}$ are ascribed to the stretching vibrations of $\mathrm{C}=\mathrm{O}$ in carboxylic groups, and $\mathrm{N}-\mathrm{H}$ bending, respectively. The strong band at $1500 \mathrm{~cm}^{-1}$ indicates the bending of $\mathrm{C}=\mathrm{C},{ }^{16}$ while the bands at $1228 \mathrm{~cm}^{-1}$ and $1143 \mathrm{~cm}^{-1}$ are the stretching vibrations of $\mathrm{C}-\mathrm{O}-\mathrm{C}$ and $\mathrm{C}-\mathrm{N}$, respectively. In addition, a weak $\mathrm{C}-\mathrm{S}$ stretching band was found at $645 \mathrm{~cm}^{-1} .{ }^{14}$ The above results verify the presence of nitrogen and sulfur, functionalized on the surface and doped into the lattice of the graphitic carbon skeleton of the N,S-GQDs. ${ }^{51}$ In addition, the structure of the $\mathrm{N}$,S-GQDs was characterized by the ${ }^{1} \mathrm{H}-\mathrm{NMR}$ and ${ }^{13} \mathrm{C}-\mathrm{NMR}$ measurements in $\mathrm{D}_{2} \mathrm{O}$ solvent as shown in Fig. S2 and S3 (ESI ), respectively. In the ${ }^{1} \mathrm{H}-\mathrm{NMR}$ spectrum, the aromatic protons are observed at 6.79-7.83 ppm indicating that an aromatic rich carbon is formed in the N,S-GQDs. The peaks from 2.81-4.51 ppm belong to $\mathrm{sp}^{3}$ carbons. Moreover, the broad peaks of $\mathrm{NH}_{2}$ in the ${ }^{1} \mathrm{H}$-NMR spectrum are also observed at $3.19 \mathrm{ppm}$ and $3.38 \mathrm{ppm}$.

In the ${ }^{13} \mathrm{C}-\mathrm{NMR}$ spectrum, the peaks from $21.4-73.3$ are the indication of the aliphatic $\mathrm{sp}^{3}$-carbons, $\mathrm{C}-\mathrm{O}$, and $\mathrm{C}-\mathrm{N}$ bonds, while the characteristic peaks of aromatic $\mathrm{sp}^{2}$-carbons were observed at around 101.9-179.9 ppm. In addition, the peaks from 173.5-179.9 are ascribed to the peak of $\mathrm{C}=\mathrm{O}$ bonds of carboxylic groups. ${ }^{55,56}$

\subsection{Fluorescence quenching of N,S-GQDs in the presence of $\mathrm{Co}^{2+}$}

Fluorescence and UV-Visible spectroscopy were used to prove the possible development of a $\mathrm{Co}^{2+}$ sensor system using GQDs, as described in Fig. 3(a and b). The results reveal that the 
(a)

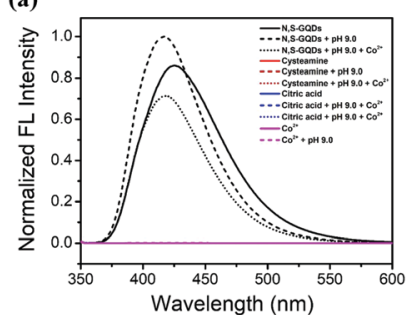

(b)

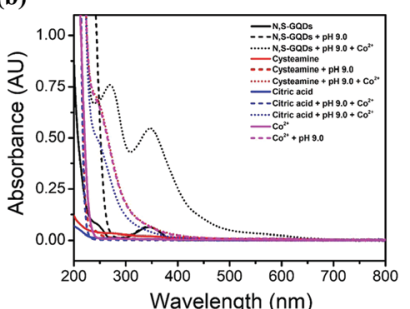

Fig. 3 (a) The normalized fluorescence emission spectra of $0.4 \mathrm{mM}$ $\mathrm{N}, \mathrm{S}$-GQDs, $0.4 \mathrm{mM} \mathrm{N}, \mathrm{S}-\mathrm{GQDs}$ in the presence of $50 \mathrm{mM}$ Tris- $\mathrm{HCl}$ buffer $\mathrm{pH}$ 9.0, and $0.4 \mathrm{mM} \mathrm{N}, \mathrm{S}-\mathrm{GQDs}$ in the presence of $50 \mathrm{mM}$ Tris- $\mathrm{HCl}$ buffer $\mathrm{pH} 9.0$ and $30 \mu \mathrm{M} \mathrm{Co}^{2+}$ compared with those of $0.4 \mathrm{mM}$ cysteamine, $0.4 \mathrm{mM}$ citric acid, and $30 \mu \mathrm{M} \mathrm{Co}^{2+}$ solutions under excitation wavelength at $345 \mathrm{~nm}$. (b) The corresponding UV-Vis absorption spectra of panel (a).

fluorescence intensity of N,S-GQDs increases under basic conditions but it is quenched after the addition of $\mathrm{Co}^{2+}$ (Fig. 3a). The absorption peaks at 270, 375, and $430 \mathrm{~nm}$ (Fig. 3b) are attributed to metal-ligand interactions, observed as the GQD solution color changes from colorless to yellow-brown. ${ }^{41}$ Consequently, both fluorescence and UV-Visible spectroscopy might be applied for the $\mathrm{Co}^{2+}$ ion detection. Given its high sensitivity, we focused on using the fluorescence to develop the sensor, evaluating parameters such as the effect of $\mathrm{pH}$, $\mathrm{N}, \mathrm{S}-\mathrm{GQD}$ concentration, and reaction time, as outlined next.

\subsection{Effect of $\mathrm{pH}$ value}

The performance of the N,S-GQDs and $\mathrm{Co}^{2+}$ systems was investigated in acidic, neutral, and basic conditions using HOAc buffers ( $\mathrm{pH} 4.5,5.0$, and 6.0), phosphate buffer ( $\mathrm{pH} 7.0$ ), TrisHCl buffers ( $\mathrm{pH}$ 8.0, 8.5, and 9.0), and Tris-NaOH buffers ( $\mathrm{pH} 10.0$ and 11.0) as shown in Fig. 4(a and b). It was found that $\mathrm{pH}$ values in the range of 8.0-9.0 resulted in high fluorescence quenching, while the $\mathrm{pH}$ value of 9.0 showed a maximum quenching effect. Therefore a Tris-HCl buffer $\mathrm{pH} 9.0$ was used throughout further experiments.

\subsection{Effect of N,S-GQD concentration}

Next, the optimal concentration of N,S-GQDs for sensing experiments was investigated. Solutions of various concentrations of N,S-GQDs (0-0.6 mM) were treated with $\mathrm{Co}^{2+}$ at $30 \mu \mathrm{M}$ in Tris$\mathrm{HCl}$ buffer solution at $\mathrm{pH}$ 9.0. Fluorescence spectra of N,S-GQDs at various concentrations in the absence and presence of $30 \mu \mathrm{M}$ $\mathrm{Co}^{2+}$ are presented in Fig. 4(c and d). The N,S-GQD fluorescence quenching was fairly constant ( $c a$. 25\%) over this concentration range and a N,S-GQD concentration of $0.2 \mathrm{mM}$ was selected for further $\mathrm{Co}^{2+}$ sensing experiments.

\subsection{Effect of reaction time}

The reaction time for interaction between GQDs and $\mathrm{Co}^{2+}$ was also optimized in the presence of $50 \mathrm{mM}$ Tris- $\mathrm{HCl}$ buffer $\mathrm{pH}$ 9.0. Various incubation times between 0 and $10 \mathrm{~min}$ were investigated as shown in Fig. 4(e and f) to determine the optimal fluorescence quenching efficiency. After mixing $\mathrm{Co}^{2+}$ ions with the probe, the color of the solution changed immediately and the fluorescence

intensity was stable after only $3 \mathrm{~min}$. Thus, we chose a reaction time of $3 \mathrm{~min}$ in all further experiments.

\subsection{Selectivity studies}

The selectivity of the proposed sensor for the detection of $\mathrm{Co}^{2+}$ was studied next using fluorescence spectroscopy as described in Fig. 5(a-c). The results suggest that while the addition of $\mathrm{Co}^{2+}$ ions caused drastic fluorescence intensity change for the N,S-GQDs, no significant change was observed upon addition of different metal cations including $\mathrm{Na}^{+}, \mathrm{K}^{+}, \mathrm{Ca}^{2+}, \mathrm{Mg}^{2+}, \mathrm{Ba}^{2+}$, $\mathrm{Al}^{3+}, \mathrm{Pb}^{2+}, \mathrm{Mn}^{2+}, \mathrm{Fe}^{3+}, \mathrm{Ni}^{2+}, \mathrm{Cu}^{2+}, \mathrm{Zn}^{2+}, \mathrm{Cd}^{2+}$, and $\mathrm{Hg}^{2+}$. These results comfirm that the fluorescent probe has a much higher selectivity towards $\mathrm{Co}^{2+}$ than other metal cations.

\subsection{Analytical performance of the sensor}

Quantitative analysis was undertaken next. The degree of fluorescence quenching $\left(F_{0}-F / F_{0}\right)$ of N,S-GQDs at different concentrations of $\mathrm{Co}^{2+}$ was monitored under the optimized conditions discussed above. The fluorescence intensity of the probe was gradually quenched by increasing the concentration of $\mathrm{Co}^{2+}$ as shown in Fig. 6a. The fluorescence intensity decreased linearly in the presence of $\mathrm{Co}^{2+}$ in the range of $0-40 \mu \mathrm{M}$ (Fig. 6b). A linear best-fit equation function of $\left(F_{0}-F\right) / F_{0}=0.0097\left[\mathrm{Co}^{2+}\right]+$ 0.0017 was determined with a correlation coefficient square $\left(R^{2}\right)$ of 0.9951 where $F_{0}$ and $F$ are the fluorescence intensities of $\mathrm{N}, \mathrm{S}$-GQDs in the absence and presence of $\mathrm{Co}^{2+}$ under the optimal conditions, respectively. From these results, the limit of detection (LOD) and limit of quantitation (LOQ) were calculated to be $1.25 \mu \mathrm{M}$ and $4.59 \mu \mathrm{M}$, respectively, according to the concentration of $\mathrm{Co}^{2+}$ required to quench GQD fluorescence intensity $\left(F_{0}-F / F_{0}\right)$ equal to 3 standard deviations of $F_{0}$ for LOD, and 10 standard deviations of $F_{0}$ for LOQ.

\subsection{The sensing mechanism}

It was reported that carboxyl, amino, and thiol groups can interact with cobalt(II) ions via the metal-ligand interaction. $^{32,36,39,40,42,45,46,57,58}$ In this work, we observed that the color of the solution changed from colorless to yellow-brown (Fig. S4, ESI $\$$ ), likely due to complexation of $\mathrm{Co}^{2+}$ with the N,S-GQDs via carboxyl, amino, and thiol groups as shown in Fig. 7. The mechanism of the accompanying fluorescence quenching of the N,S-GQDs was investigated next using a variety of analytical techniques including TEM, and zeta potential analysis.

The absorption peaks at 270 and $375 \mathrm{~nm}$ of the N,S-GQDs in neat solution were incrementally increased without significant shift in the presence of $\mathrm{Co}^{2+}$, however a broad new absorption band around $430 \mathrm{~nm}$ was observed attributed to complex formation (Fig. 8a). As already seen in Fig. 3a, the fluorescence spectra of N,S-GQDs in the absence and presence of Tris- $\mathrm{HCl}$ buffer at pH 9.0 feature emission peaks at $425 \mathrm{~nm}$ and $417 \mathrm{~nm}$, respectively. In addition, the intensity of the peak was decreased in basic solution and shifted to shorter wavelength (blue shift) by $8 \mathrm{~nm}$. This may indicate that the size of the GQDs decreased in basic solution at $\mathrm{pH}$ 9.0. Furthermore, the emission peak of the GQDs at $\mathrm{pH} 9.0$ and in the presence of $\mathrm{Co}^{2+}$ was 
(a)

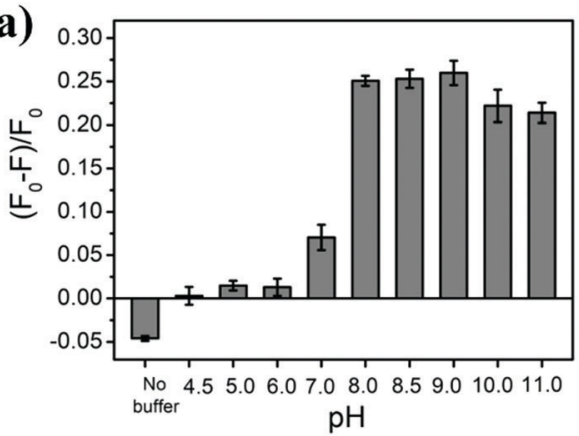

(c)

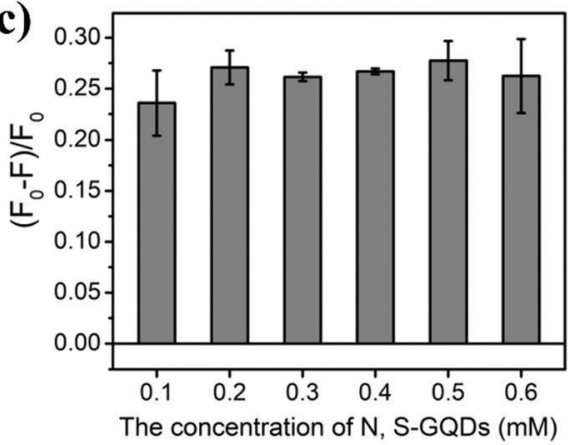

(e)

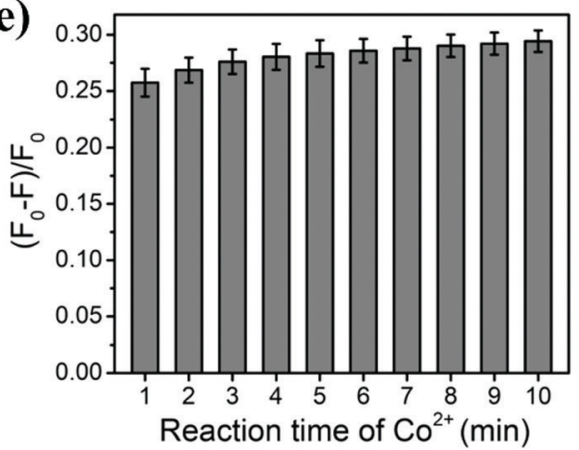

(b)

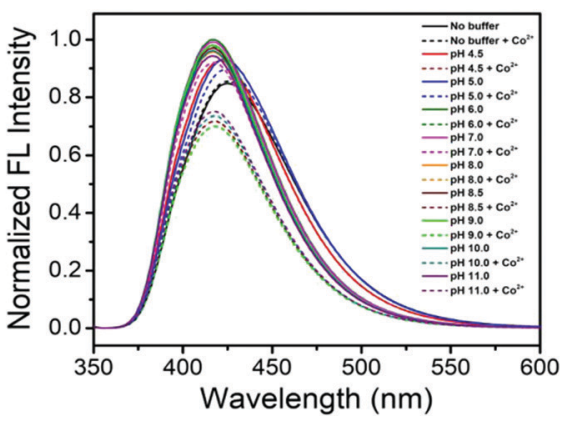

(d)

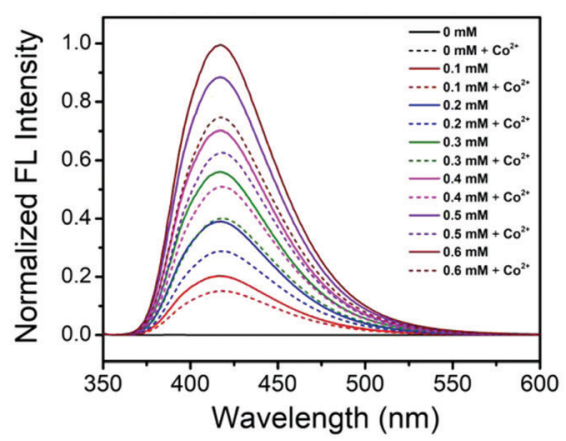

(f)

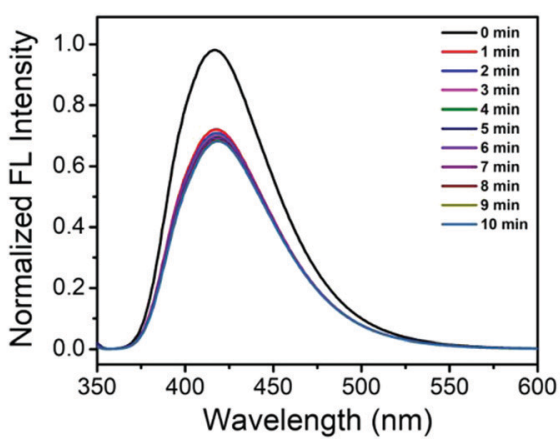

Fig. 4 (a) The degree of fluorescence quenching $\left(F_{0}-F / F_{0}\right)$ of $0.4 \mathrm{mM} \mathrm{N}, \mathrm{S}-\mathrm{GQDs}$ after treatment with $30 \mu \mathrm{M} \mathrm{Co} \mathrm{O}^{2+}$ in $50 \mathrm{mM}$ buffer solutions at different $\mathrm{pHs}$ from 4.5 to 11.0. (b) The corresponding fluorescence emission spectra for the data in panel (a). (c) The degree of fluorescence quenching $\left(F_{0}-F / F_{0}\right)$ of different concentrations of N,S-GQDs from 0 to $0.6 \mathrm{mM}$ after treatment with $30 \mu \mathrm{M} \mathrm{Co}{ }^{2+}$ in $50 \mathrm{mM}$ Tris- $\mathrm{HCl}$ buffer solution at $\mathrm{pH} 9.0$. (d) The corresponding fluorescence emission spectra for the data in panel (c). (e) The degree of fluorescence quenching $\left(F_{0}-F / F_{0}\right)$ of $0.2 \mathrm{mM} \mathrm{N}, \mathrm{S}-\mathrm{GQDs}$ after treatment with $30 \mu \mathrm{M}$ $\mathrm{Co}^{2+}$ from $\mathrm{O}$ to $10 \mathrm{~min}$ in $50 \mathrm{mM}$ Tris- $\mathrm{HCl}$ buffer at $\mathrm{pH}$ 9.0. (f) The corresponding fluorescence emission spectra for the data in panel (e).

quenched and shifted to a longer wavelength (red shift) by about $3 \mathrm{~nm}$. This implies that $\mathrm{Co}^{2+}$ can interact with functional groups on the surface of GQDs through metal-ligand interaction causing an increasing particle size (aggregation) of N,S-GQDs.

To confirm this hypothesis, TEM was used to investigate GQD particle size (Fig. S5a-c, ESI $\ddagger$ ). It was clearly observed that the size of the GQDs was smaller after adding Tris-HCl buffer $\mathrm{pH}$ at 9.0 and the GQDs were well-dispersed with an average diameter of $1.8 \pm 0.5 \mathrm{~nm}$. However the particle size of the GQDs was increased to $2.2 \pm 0.4 \mathrm{~nm}$ after the addition of $\mathrm{Co}^{2+}$. This indicates that the complexation of GQDs and metal ions indeed leads to aggregation of GQDs, causing both a color change and fluorescence quenching.

The zeta potential of the N,S-GQDs was reduced from +50.24 to $-31.28 \mathrm{mV}$ after addition of buffer $\mathrm{pH} 9.0$ as shown in Fig. $8 \mathrm{~b}$. The significant reduction of zeta potential values suggests the deprotonation of the functional groups on the surface of the GQDs leaving an overall negative charge. This change makes the GQDs effectively stronger Lewis bases which can easily interact with $\mathrm{Co}^{2+}$ metal ions. When a solution of $30 \mu \mathrm{M}$ of $\mathrm{Co}^{2+}$ ions was added to the GQDs in basic conditions at buffered $\mathrm{pH} 9.0$, the zeta potential increased to $+23.22 \mathrm{mV}$, indicating $\mathrm{Co}^{2+}$ indeed interacts with the negatively charged GQDs. The deprotonated functional groups on the surface of N,S-GQDs, including carboxyl, amino, and thiol groups, can bind with $\mathrm{Co}^{2+}$ ions through metal-ligand interactions leading to the reduction of the anionic character of the GQDs.

Furthermore, a Stern-Volmer plot was used to give insight into the quenching mechanism, given as $F_{0} / F=1+K_{\mathrm{sv}}[\mathrm{Q}]$, where $F_{0}$ and $F$ are the fluorescence intensities of N,S-GQDs in the absence and presence of $\mathrm{Co}^{2+}, K_{\mathrm{sv}}$ is the Stern-Volmer quenching constant, and [Q] is the concentration of quencher $\left(\mathrm{Co}^{2+}\right)$. 

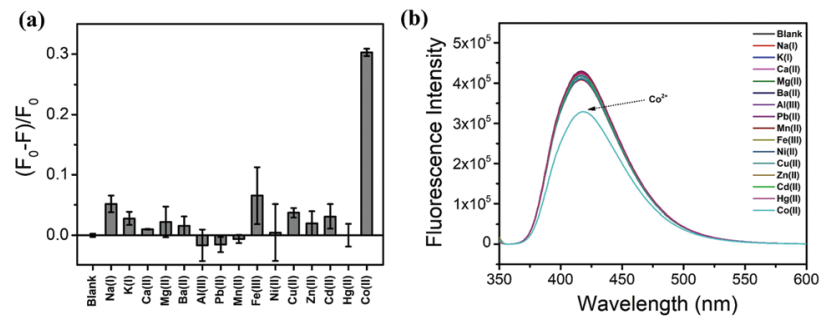

(c)

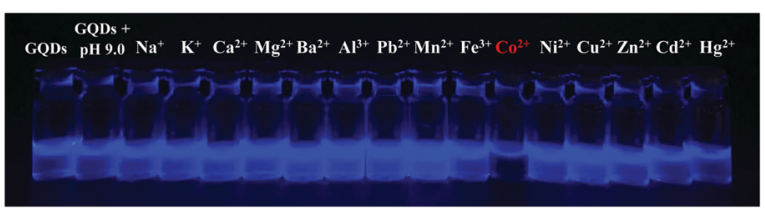

Fig. 5 (a) The degree of fluorescence quenching $\left(F_{0}-F / F_{0}\right)$ of $0.2 \mathrm{mM}$ $\mathrm{N}, \mathrm{S}-\mathrm{GQDS}$ in the presence of $30 \mu \mathrm{M} \mathrm{Co}^{2+}$ and various other cations in $50 \mathrm{mM}$ Tris $-\mathrm{HCl}$ buffer solution at $\mathrm{pH}$ 9.0. (b) The fluorescence emission spectra for the data in panel (a). (c) Photographs of the emission of $20 \mathrm{mM}$ $\mathrm{N}, \mathrm{S}-\mathrm{GQDs}$ in the presence of $1 \mathrm{mM}$ concentrations of various cations in $500 \mathrm{mM}$ Tris- $\mathrm{HCl}$ buffer solution at $\mathrm{pH} 9.0$ and under UV light irradiation of $365 \mathrm{~nm}$.
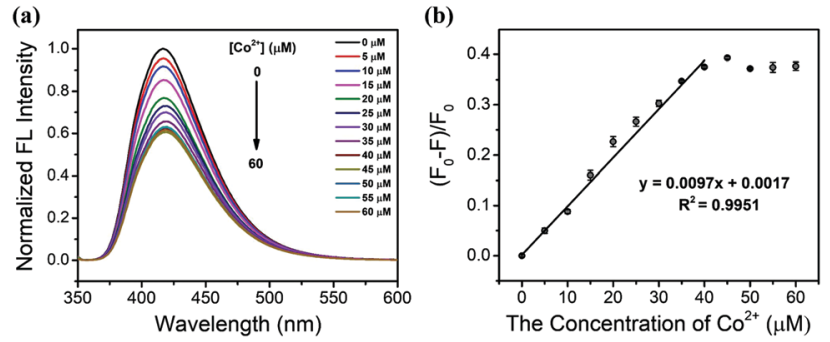

Fig. 6 (a) The normalized fluorescence emission spectra of $0.2 \mathrm{mM}$ N,S-GQDs after treatment with different concentrations of $\mathrm{Co}^{2+}$ from 0 to $60 \mu \mathrm{M}$ in $50 \mathrm{mM}$ Tris- $\mathrm{HCl}$ buffer solution at $\mathrm{pH}$ 9.0. (b) The degree of GQD fluorescence quenching $\left(F_{0}-F / F_{0}\right)$ as a function of $\mathrm{Co}^{2+}$ concentration.

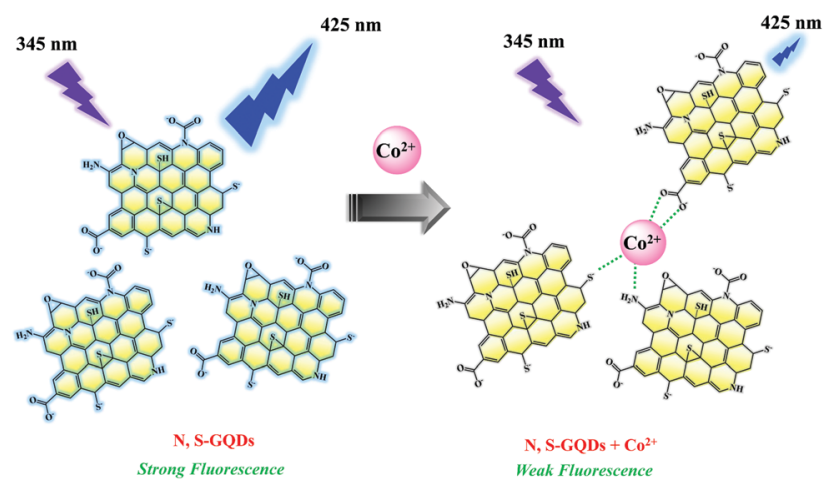

Fig. 7 Schematic representation of the complexation of $\mathrm{Co}^{2+}$ and N,S-GQDs via metal-ligand interactions and accompanying fluorescence quenching.

From the Stern-Volmer plot as shown in Fig. 8c, the curve is linear for $\mathrm{Co}^{2+}$ concentrations from 0 to $40 \mu \mathrm{M}$. A linear SternVolmer plot can result from either a purely dynamic (diffusive) queching mechanism, or a purely static (due to complexation) quenching mechanism. The calculated $K_{\mathrm{sv}}$ after fitting a linear curve to the Stern-Volmer plot was found to be $1.52 \times 10^{4} \mathrm{M}^{-1}$ (a)
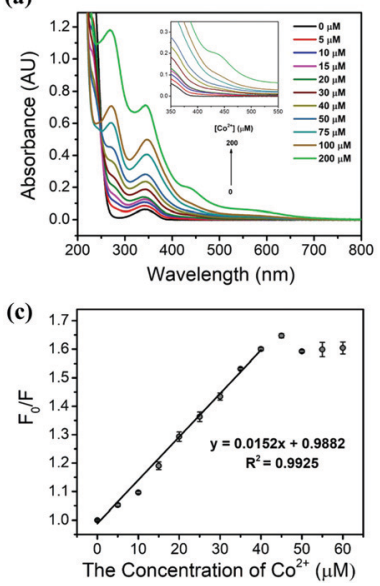

(b)

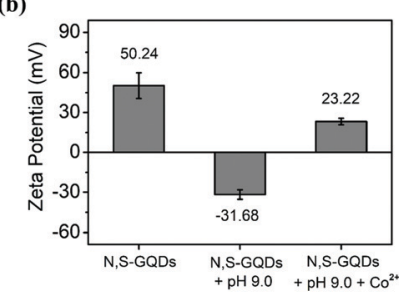

(d)

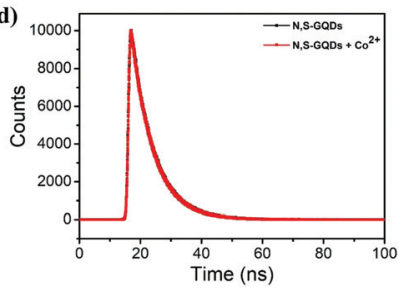

Fig. 8 (a) UV-Visible spectra of $0.2 \mathrm{mM} \mathrm{N}, S-G Q D s$ in $50 \mathrm{mM}$ Tris- $\mathrm{HCl}$ buffer solution at pH 9.0 in the presence of various concentrations of $\mathrm{Co}^{2+}$ ions (from bottom to top, 0 to $200 \mu \mathrm{M}$ ). Inset is the increasing of the absorbance of a broad new absorption band at around $430 \mathrm{~nm}$. (b) The zeta potential of neat $0.2 \mathrm{mM} \mathrm{N}, \mathrm{S}-\mathrm{GQDs}$, and in the presence of $50 \mathrm{mM}$ Tris- $\mathrm{HCl}$ buffer at $\mathrm{pH} 9.0$, and $30 \mu \mathrm{M} \mathrm{Co}^{2+}$. (c) Stern-Volmer relationship for fluorescence quenching of the N,S-GQDs by $\mathrm{Co}^{2+}$. (d) Fluorescence decay curves of $20 \mu \mathrm{M} \mathrm{N}, \mathrm{S}-\mathrm{GQDs}$ in $50 \mathrm{mM}$ Tris- $\mathrm{HCl}$ buffer solution at pH 9.0 in the absence (black) and presence (red) of $30 \mu \mathrm{M} \mathrm{Co}^{2+}$ ions.

$\left(R^{2}=0.9925\right)$, and this constant relates to an equilibrium constant for the binding of $\mathrm{Co}^{2+}$ on the surface of N,S-GQDs, assuming a static quenching mechanism. ${ }^{59}$ Confirmation of the static quenching mechanism comes from time-resolved fluorescence studies. The fluorescence decay of N,S-GQDs was obtained in the absence and presence of $\mathrm{Co}^{2+}$ as shown in Fig. 8d. The lifetimes of the N,S-GQDs and N,S-GQDs/ $\mathrm{Co}^{2+}$ systems were $8.16 \mathrm{~ns}$ and $8.10 \mathrm{~ns}$, respectively, almost the same despite the evidence of significant fluorescence quenching from steady state studies. Thus, complexation of N,S-GQDs by $\mathrm{Co}^{2+}$ leads to complete fluorescence quenching, and any fluorescence observed is due to uncomplexed N,S-GQDs. ${ }^{60}$

\subsection{Application of N,S-GQDs for the determination of $\mathrm{Co}^{2+}$ ions in water samples}

Next, the performance of the proposed $\mathrm{Co}^{2+}$ sensor was investigated with real water samples from the Khon Kaen University, consisting of commercial drinking water, dispenser drinking water (from the second floor of the chemistry building), and tap water (from the inorganic laboratory at the chemistry building). The concentration of $\mathrm{Co}^{2+}$ and recoveries were measured using the standard addition method by spiking known concentrations of $\mathrm{Co}^{2+}$ ions $(5,10$ and $15 \mu \mathrm{M})$ into each sample, which were diluted to be within the working linear range. As shown in Table 1, the results showed a good agreement between the expected and found values with $91.2-108.2 \%$ of recovery and $0.1-7.3 \%$ of relative standard deviation (RSD).

\subsection{Comparison with other methods for cobalt determination}

In recent years, many methods have been reported for the detection of $\mathrm{Co}^{2+}$ ions, and some examples are shown in Table 2 . 
Table 1 Determination of $\mathrm{Co}^{2+}$ concentration in real water samples

\begin{tabular}{lrrr}
\hline & Amount of standard & \multicolumn{2}{c}{ Proposed method $(n=3)$} \\
\cline { 4 - 5 } \cline { 4 - 4 } Water sample studied & $\mathrm{Co}^{2+}$ ions added $(\mu \mathrm{M})$ & \%Recovery \pm SD & RSD $(\%)$ \\
\hline Commercial drinking & 5 & $105.41 \pm 7.66$ & 7.27 \\
water & 10 & $108.16 \pm 0.97$ & 0.89 \\
& 15 & $101.44 \pm 4.14$ & 4.08 \\
& & & \\
Drinking water (from & 5 & $91.17 \pm 0.09$ & 0.10 \\
water dispenser) & 10 & $98.55 \pm 2.49$ & 2.53 \\
& 15 & $99.25 \pm 2.82$ & 2.85 \\
Tap water (from & 5 & & \\
inorganic laboratory) & 10 & $100.19 \pm 4.53$ & 4.52 \\
& 15 & $98.50 \pm 6.26$ & 6.36 \\
& & $100.46 \pm 0.36$ & 0.36
\end{tabular}

These techniques include electrochemistry, colorimetry, and fluorescence spectroscopy. However, the majority of these procedures exhibit some limitations, such as requiring extensive pre-treatments before measurement, expensive instrumentation, or lengthy analysis times. Although, some techniques show detection limits far lower than that of this work, $\mathrm{Co}^{2+}$ sensors do not always need to achieve ultra-low limits of detection to be useful. The normal amounts of $\mathrm{Co}^{2+}$ in human blood and urine are $0.18 \mu \mathrm{g} \mathrm{L}^{-1}(0.003 \mu \mathrm{M})$ and $1.0 \mu \mathrm{g} \mathrm{L}^{-1}(0.017 \mu \mathrm{M})$, respectively. When the serum $\mathrm{Co}^{2+}$ concentration is greater than $1.0 \mu \mathrm{g} \mathrm{L}^{-1}$, it is considered as excessive cobalt exposure. A value greater than $5 \mu \mathrm{g} \mathrm{L}^{-1}(0.085 \mu \mathrm{M})$ can be toxic. ${ }^{36}$ Thus, the procedures for the determination of $\mathrm{Co}^{2+}$ which have a higher limit of detection than the normal level of $\mathrm{Co}^{2+}$ in the body are important as they can indicate abnormal excess of $\mathrm{Co}^{2+}$. For instance, if $\mathrm{Co}^{2+}$ levels in serum reach $7 \mathrm{ng} \mathrm{mL}^{-1}(0.12 \mu \mathrm{M})$, peripheral neuropathy, sensorineural hearing loss, visual loss due to retinal-optic nerve damage, hypothyroidism, and cardiomyopathy are possible. ${ }^{61}$ Importantly, our detection limit and working linear range envelope the typical physiological levels of $\mathrm{Co}^{2+}$, with the sensor also exhibiting remarkable simplicity, selectivity, and low-cost. (a)

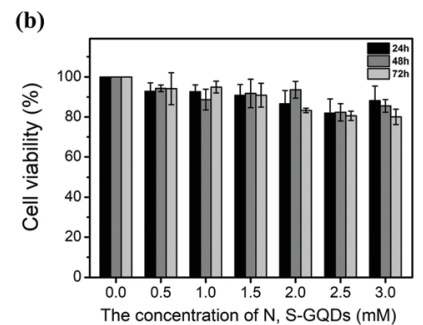

Fig. 9 (a) N,S-GQD-based paper strips for visual and rapid sensing and screening of $\mathrm{Co}^{2+}$ under UV light irradiation of $365 \mathrm{~nm}$. (b) Cellular toxicity determined by MTT assay with HeLa cells upon 24, 48, and 72 hours of incubation with different concentrations of N,S-GQDs from 0.0 to $3.0 \mathrm{mM}$.

\subsection{The screening of $\mathrm{Co}^{2+}$ ions by the N,S-GQD-based paper strips}

N,S-GQD-based paper strips were developed next as an avenue for the rapid, visual sensing of $\mathrm{Co}^{2+}$ ion concentrations. Fig. 9a shows the fluorescence from GQD paper strips made by immersing the strips into N,S-GQDs in buffer solution $\mathrm{pH}$ 9.0. After dropping $\mathrm{Co}^{2+}$ solutions with concentrations of $200,400,600,800$, and $1000 \mu \mathrm{M}$ onto the strips, they were rinsed and fluorescence images and spectra were taken. The emission from the paper strips darkened gradually with increasing $\mathrm{Co}^{2+}$ concentration in the range of $0-1000 \mu \mathrm{M}$. The result confirms that the addition of $\mathrm{Co}^{2+}$ causes the fluorescence quenching of the sensor probe which could be applied to screen $\mathrm{Co}^{2+}$ with low-cost and simple paper strip sensors with a rapid response.

\subsection{Cell toxicity}

The cellular toxicity of the N,S-GQDs was assessed by MTT assay using HeLa cells. As shown in Fig. 9b, the N,S-GQDs have low cytotoxicity with more than $80 \%$ of the cells remaining viable upon addition of $\mathrm{N}, \mathrm{S}-\mathrm{GQDS}$ over a concentration range of 0.5-3.0 $\mathrm{mM}$ and after incubation for 24,48 , and 72 hours.

Table 2 Comparison of the performance of several $\mathrm{Co}^{2+}$ ion sensing systems

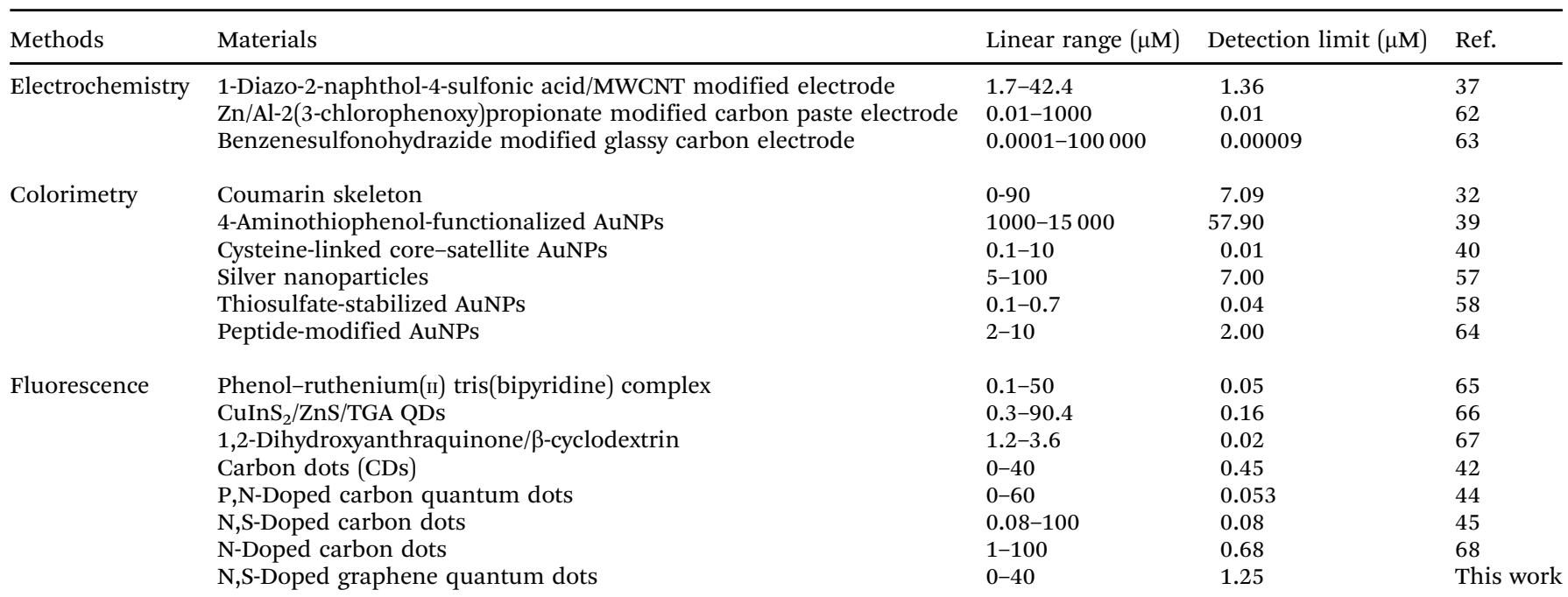

Abbreviations: MWCNTs, multiwalled carbon nanotubes; AuNPs, gold nanoparticles; $\mathrm{CuInS}_{2} / \mathrm{ZnS} / \mathrm{TGA}$ QDs, thioglycolic acid-capped CuInS $2 / \mathrm{ZnS}$ quantum dots. 
These results demonstrate the biocompatibility of the N,S-GQDs, which suggests that they may potentially be applied to biological systems.

\section{Conclusions}

We have successfully synthesized N,S-GQDs through a hydrothermal synthesis method as a sensitive and selective fluorescent probe for the detection of $\mathrm{Co}^{2+}$. The fluorescence intensity of N,S-GQDs was quenched after the addition of $\mathrm{Co}^{2+}$ due to metal-ligand binding interactions (a change from colorless to yellow-brown also occurs). Our proposed sensor provides a feasible approach to quantitative detection of $\mathrm{Co}^{2+}$ with high selectivity towards $\mathrm{Co}^{2+}$ over other metal ions. This sensor has a LOD and LOQ of $1.25 \mu \mathrm{M}$ and $4.59 \mu \mathrm{M}$, respectively, and good linear response to $\mathrm{Co}^{2+}$ in the range of $0-40 \mu \mathrm{M}$, ideal for testing of abnormal excess of $\mathrm{Co}^{2+}$ diseases in humans. The $\mathrm{N}, \mathrm{S}-\mathrm{GQDS}$ can be applied for the detection of $\mathrm{Co}^{2+}$ in real water using the standard addition method with satisfactory results. In addition, N,S-GQD-based paper strips were successfully applied for the rapid and visual screening of $\mathrm{Co}^{2+}$. More importantly, the N,S-GQDs have low cytotoxicity and so the proposed sensor might be very useful to apply in environmental and biological fields as described in recent reports. ${ }^{69-73}$

\section{Conflicts of interest}

There are no conflicts to declare.

\section{Acknowledgements}

W. B. was supported by Development and Promotion of Science and Technology Talents Project (DPST). C. T. was supported by The Science achievement scholarship of Thailand (SAST). S. K. acknowledges the financial and laboratory support from Faculty of Science, Khon Kaen University, the Center of Excellence for Innovation in Chemistry (PERCH-CIC), Ministry of Higher Education, Science, Research and Innovation and Mekong Health Science Research Institute Khon Kaen University. We thank Dr Narong Chanlek for XPS test support at BL 5.3 and Mr Anuchit Ruangvittayanon for HRTEM measurement at Synchrotron Light Research Institute (SLRI), Thailand.

\section{References}

1 A. Cayuela, M. L. Soriano, C. Carrillo-Carrión and M. Valcárcel, Chem. Commun., 2016, 52, 1311-1326.

2 H. Sun, L. Wu, W. Wei and X. Qu, Mater. Today, 2013, 16, 433-442.

3 Z. Zhang, J. Zhang, N. Chen and L. Qu, Energy Environ. Sci., 2012, 5, 8869-8890.

4 J. Shen, Y. Zhu, X. Yang and C. Li, Chem. Commun., 2012, 48, 3686-3699.

5 S. N. Baker and G. A. Baker, Angew. Chem., Int. Ed., 2010, 49, 6726-6744.

6 A. K. Geim and K. S. Novoselov, Nat. Mater., 2007, 6, 183-191.
7 D. Pan, J. Zhang, Z. Li and M. Wu, Adv. Mater., 2010, 22, 734-738.

8 X. Hai, J. Feng, X. Chen and J. Wang, J. Mater. Chem. B, 2018, 6, 3219-3234.

9 S. Sangam, A. Gupta, A. Shakeel, R. Bhattacharya, A. K. Sharma, D. Suhag, S. Chakrabarti, S. K. Garg, S. Chattopadhyay, B. Basu, V. Kumar, S. K. Rajput, M. K. Dutta and M. Mukherjee, Green Chem., 2018, 20, 4245-4259.

10 A. Suryawanshi, M. Biswal, D. Mhamane, R. Gokhale, S. Patil, D. Guin and S. Ogale, Nanoscale, 2014, 6, 11664-11670.

11 X. T. Zheng, A. Ananthanarayanan, K. Q. Luo and P. Chen, Small, 2015, 11, 1620-1636.

12 S. Zhu, S. Tang, J. Zhang and B. Yang, Chem. Commun., 2012, 48, 4527-4539.

13 L. Chen, G. Yang, P. Wu and C. Cai, Biosens. Bioelectron., 2017, 96, 294-299.

14 T. K. Mondal, D. Dinda and S. K. Saha, Sens. Actuators, B, 2018, 257, 586-593.

15 C. Qu, D. Zhang, R. Yang, J. Hu and L. Qu, Spectrochim. Acta, Part A, 2019, 206, 588-596.

16 D. Qu, M. Zheng, P. Du, Y. Zhou, L. Zhang, D. Li, H. Tan, Z. Zhao, Z. Xie and Z. Sun, Nanoscale, 2013, 5, 12272-12277.

17 V. Sharma and P. K. Jha, Sol. Energy Mater. Sol. Cells, 2019, 200, 109908-109915.

18 Y. Gao, S. Zhong, L. Xu, S. He, Y. Dou, S. Zhao, P. Chen and X. Cui, Microporous Mesoporous Mater., 2019, 278, 130-137.

19 Y. Jing, Y. Zhu, X. Yang, J. Shen and C. Li, Langmuir, 2011, 27, 1175-1180.

20 J. H. Liu, R. S. Li, B. Yuan, J. Wang, Y. F. Li and C. Z. Huang, Nanoscale, 2018, 10, 17402-17408.

21 L. Li, G. Wu, G. Yang, J. Peng, J. Zhao and J.-J. Zhu, Nanoscale, 2013, 5, 4015-4039.

22 Y. Li, Y. Zhao, H. Cheng, Y. Hu, G. Shi, L. Dai and L. Qu, J. Am. Chem. Soc., 2012, 134, 15-18.

23 Y. Park, J. Yoo, B. Lim, W. Kwon and S. W. Rhee, J. Mater. Chem. A, 2016, 4, 11582-11603.

24 P. Wu, T. Zhao, S. Wang and X. Hou, Nanoscale, 2014, 6, 43-64.

25 N.-u. Amin and T. Ahmad, RSC Adv., 2015, 5, 14322-14329.

26 L. Järup, Br. Med. Bull., 2003, 68, 167-182.

27 D. G. Barceloux and D. Barceloux, J. Toxicol., Clin. Toxicol., 1999, 37, 201-216.

28 H. B. Castellanos-Sinco, C. O. Ramos-Peñafiel, A. SantoyoSánchez, J. Collazo-Jaloma, C. Martínez-Murillo, E. MontañoFigueroa and A. Sinco-Ángeles, Rev. Med. Hosp. Gen., 2015, 78, 135-143.

29 S. Elliott, Br. J. Pharmacol., 2008, 154, 529-541.

30 T. Kawakami, N. Hanao, K. Nishiyama, Y. Kadota, M. Inoue, M. Sato and S. Suzuki, Toxicol. Appl. Pharmacol., 2012, 258, 32-42.

31 S. L. Roderick and B. W. Matthews, Biochemistry, 1993, 32, 3907-3912.

32 D. Vashisht, K. Kaur, R. Jukaria, A. Vashisht, S. Sharma and S. K. Mehta, Sens. Actuators, B, 2019, 280, 219-226.

33 I. Sheikh, J. Med. Toxicol., 2016, 2, 1-6.

34 R. Lauwerys and D. Lison, Sci. Total Environ, 1994, 150, 1-6. 
35 D. Lison, M. De Boeck, V. Verougstraete and M. KirschVolders, Occup. Environ. Med., 2001, 58, 619-625.

36 A. Mirabi, A. S. Rad and M. Abdollahi, ChemistrySelect, 2017, 2, 4439-4444.

37 M. Zamhari, A. Numnuam, W. Limbut, P. Kanatharana and P. Thavarungkul, Electroanalysis, 2017, 29, 2348-2357.

38 M. Bartosiak, K. Jankowski and J. Giersz, J. Pharm. Biomed. Anal., 2018, 155, 135-140.

39 U. B. Patel, V. N. Mehta, M. A. Kumar and S. K. Kailasa, Res. Chem. Intermed., 2013, 39, 771-779.

40 F. Mazur, L. Liu, H. Li, J. Huang and R. Chandrawati, Sens. Actuators, B, 2018, 268, 182-187.

41 A. H. Gore, D. B. Gunjal, M. R. Kokate, V. Sudarsan, P. V. Anbhule, S. R. Patil and G. B. Kolekar, ACS Appl. Mater. Interfaces, 2012, 4, 5217-5226.

42 D. Kong, F. Yan, Z. Han, J. Xu, X. Guo and L. Chen, RSC Adv., 2016, 6, 67481-67487.

43 N. Jing, M. Tian, Y. Wang and Y. Zhang, J. Lumin., 2019, 206, 169-175.

44 S. Liao, F. Zhu, X. Zhao, H. Yang and X. Chen, Sens. Actuators, B, 2018, 260, 156-164.

45 Y. Chen, P. Shang, Y. Dong and Y. Chi, Sens. Actuators, B, 2017, 242, 1210-1215.

46 L. Zi, Y. Huang, Z. Yan and S. Liao, J. Lumin., 2014, 148, 359-363.

47 Z. L. Wu, M. X. Gao, T. T. Wang, X. Y. Wan, L. L. Zheng and C. Z. Huang, Nanoscale, 2014, 6, 3868-3874.

48 S. Qu, X. Wang, Q. Lu, X. Liu and L. Wang, Angew. Chem., Int. Ed., 2012, 51, 12215-12218.

49 S. Wang, L. Zhang, Z. Xia, A. Roy, D. W. Chang, J.-B. Baek and L. Dai, Angew. Chem., Int. Ed., 2012, 51, 4209-4212.

50 J. Liang, Y. Jiao, M. Jaroniec and S. Z. Qiao, Angew. Chem., Int. Ed., 2012, 51, 11496-11500.

51 R. Zhang, J. R. Adsetts, Y. Nie, X. Sun and Z. Ding, Carbon, 2018, 129, 45-53.

52 H. Ding, Y. Ji, J.-S. Wei, Q.-Y. Gao, Z.-Y. Zhou and H.-M. Xiong, J. Mater. Chem. B, 2017, 5, 5272-5277.

53 R. Zhang and W. Chen, Biosens. Bioelectron., 2014, 55, 83-90.
54 C. Chaicham, T. Tuntulani, V. Promarak and B. Tomapatanaget, Sens. Actuators, B, 2019, 282, 936-944.

55 L. Song, J. Shi, J. Lu and C. Lu, Chem. Sci., 2015, 6, 4846-4850. 56 S. Zhu, Q. Meng, L. Wang, J. Zhang, Y. Song, H. Jin, K. Zhang, H. Sun, H. Wang and B. Yang, Angew. Chem., Int. Ed., 2013, 52, 3953-3957.

57 Y. Yao, D. Tian and H. Li, ACS Appl. Mater. Interfaces, 2010, 2, 684-690.

58 Z. Zhang, J. Zhang, T. Lou, D. Pan, L. Chen, C. Qu and Z. Chen, Analyst, 2012, 137, 400-405.

59 S. Kulchat, W. Boonta, A. Todee, P. Sianglam and W. Ngeontae, Spectrochim. Acta, Part A, 2018, 196, 7-15.

60 D. Su, M. Wang, Q. Liu, Z. Qu and X. Su, New J. Chem., 2018, 42, 17083-17090.

61 R. Yu, Journal of Endocrinology and Thyroid Research, 2017, 1, 1-4.

62 I. M. Isa, S. Nur, A. Dahlan, N. Hashim, M. Ahmad and S. Ghani, Int. J. Electrochem. Sci., 2012, 7, 7797-7808.

63 M. M. Hussain, A. M. Asiri, M. N. Arshad and M. M. Rahman, Chem. Eng. J., 2018, 339, 133-143.

64 M. Zhang, Y.-Q. Liu and B.-C. Ye, Analyst, 2012, 137, 601-607. 65 C.-Y. Li, X.-B. Zhang, Z. Jin, R. Han, G.-L. Shen and R.-Q. Yu, Anal. Chim. Acta, 2006, 580, 143-148.

66 L. Zi, Y. Huang, Z. Yan and S. Liao, J. Lumin., 2014, 148, 359-363. 67 S. Mohandoss and T. Stalin, RSC Adv., 2017, 7, 16581-16593.

68 X. Wen, L. Shi, G. Wen, Y. Li, C. Dong, J. Yang and S. Shuang, Sens. Actuators, B, 2016, 235, 179-187.

69 X. Tan, Y. Li, X. Li, S. Zhou, L. Fan and S. Yang, Chem. Commun., 2015, 51, 2544-2546.

70 S. Li, S. Zhou, Y. Li, X. Li, J. Zhu, L. Fan and S. Yang, ACS Appl. Mater. Interfaces, 2017, 9, 22332-22341.

71 M. Zhang, L. Bai, W. Shang, W. Xie, H. Ma, Y. Fu, D. Fang, H. Sun, L. Fan, M. Han, C. Liu and S. Yang, J. Mater. Chem., 2012, 22, 7461-7467.

72 R. Guo, S. Zhou, Y. Li, X. Li, L. Fan and N. H. Voelcker, ACS Appl. Mater. Interfaces, 2015, 7, 23958-23966.

73 Y. Liu, S. Zhou, L. Fan and H. Fan, Microchim. Acta, 2016, 183, 2605-2613. 